\title{
Do Canônico e do Hegemônico na Apropriação do Preconceito Racial em Crianças
}

\author{
The Canonic and the Hegemonic in the Appropriation of the Racial Prejudice in \\ Children \\ Del Canónico y del Hegemónico en la Apropiación del Prejuicio Racial entre los Niños \\ Rebeca Oliveira Duarte ${ }^{l}$ \\ Antonio Roazzi $i^{2}$ \\ Universidade Federal de Pernambuco
}

As narrativas podem ser o último recurso dos teóricos econômicos. Mas elas provavelmente são a matéria da vida daqueles cujo comportamento eles estudam. (Bruner, Realidade Mental, Mundos Possiveis, 2002, p. 45)

\begin{abstract}
Resumo
Este estudo visa trazer a reflexão sobre a apropriação do racismo entre crianças, relacionando os construtos do canônico, examinado por Bruner em sua obra Actos de Significado (2008), e do hegemônico em Gramsci, em Cadernos do Cárcere (tradução, 2004). Sob essas conceituações, são trazidas as formulações a respeito de como a criança realiza a habilidade de marcar o que é culturalmente canônico, relacionando-as aos conceitos de hegemonia, ideologia e senso comum. Se a estrutura narrativa possibilita compreensões ainda pré-linguísticas de significados (Bruner, 2008), conclui-se que haveria o início de uma internalização do racismo hegemônico anterior mesmo à expressão linguística pela criança, sugerindo reflexões acerca da superação do preconceito racial na infância. Palavras-chave: Canonicidade; Hegemonia; Racismo.
\end{abstract}

\begin{abstract}
This study aims to discuss the first appropriations of racial prejudice in children taking into account the canonical forms examined by Bruner in his book Acts of Meaning (2008) and the hegemonic concept by Gramsci in Cadernos do Cárcere (2004). Using these concepts, the development of abilities with which children perceive the canonical forms of culture, linking these ideas with the concepts of hegemony, ideology, and common sense are discussed. If the narrative structure allows for a pre-linguist comprehension of meaning (Bruner, 2008), we conclude that an internalization of hegemonic racism would begin prior to a child's acquisition of linguistic expression, which in turn allows us to consider ways in which to overcome racial prejudice in infancy.

Key-words: Canonical forms; Hegemony; Racism.
\end{abstract}

\section{Resumen}

Este estudio pretende reflexionar sobre las primeras apropiaciones del prejuicio racial entre los niños, a partir de los constructos del canónico, examinados por los estudios de Bruner en Actos de Significado (2008), y del hegemónico en Gramsci, en Cadernos do Cárcere (traducción, 2004). A través de estos conceptos, levanto las formulaciones al respecto de cómo el niño realiza la habilidad de marcar lo que es culturalmente canónico, relacionándolas a los conceptos de hegemonía, ideología y sentido común. Si la estructura narrativa posibilita comprensiones aun pre-lingüísticas de significados (Bruner, 2008), concluimos que habría el inicio de una internalización del racismo hegemónico que es anterior a la expresión lingüística del niño, sugiriendo reflexiones acerca de la superación del prejuicio racial en la niñez.

Palabras-clave: Canónico; Hegemonía; Racismo.

\section{Apresentação}

Jerome Bruner é enfático quanto ao lugar da narrativa na condição humana: simplesmente transformamos nossas experiências no mundo em narrativas, sendo estas um dos mecanismos psicológicos básicos para o ser humano e os grupos sociais e culturais nos quais está inserido. Ainda mais, para esse autor, costumamos viver em um mundo construído e obediente às regras e aos recursos da

Endereço 1: Rua Des. Altino, 107, C1, Várzea. Recife/PE, CEP 50810-390.

Endereço 2: $\mathrm{CFCH} 80$ andar, Av. Arquitetura s/n, Cidade

Universitária, CEP 50740-550, Recife PE, Brasil narrativa, e é através das gramáticas das narrativas que os indivíduos constroem a realidade psicológica e cultural dos participantes das histórias. A importância da narrativa é ainda mais sentida durante os primeiros anos de vida da criança, não somente pelos aspectos cognitivos que a caracterizam, como também pelo valor de troca social em decorrência do fato que o pensamento narrativo apresenta valências cognitivas e emocionais.

O presente estudo visa a alavancar reflexões acerca desse lugar da narrativa na organização das experiências, mais especificamente partindo do conceito do canônico, que virá a ser examinado aqui pelos estudos de Jerome Bruner em sua obra Actos de 
Significado (2008), propondo um diálogo deste com o conceito do hegemônico em Antonio Gramsci, em seu Cadernos do Cárcere (tradução, 2004). Sob essas conceituações, procuramos seguir as formulações de Bruner a respeito de como a criança obtém o poder da narrativa, ou, em outras palavras, realiza a habilidade de marcar o que é culturalmente canônico e também de explicar os desvios e rupturas desses cânones, marcando as intersecções com a questão da hegemonia, da ideologia e do senso comum de Gramsci.

Tal escolha se ancora em investigações a respeito das primeiras formulações de preconceito racial em crianças pequenas; entendemos que Bruner, trazendo este um amplo apoio epistemológico, fornece pistas quando situa a narrativa não simplesmente como uma realização mental, mas enquanto uma realização de prática social, afirmando inclusive que a estrutura narrativa habita a práxis da interação social antes mesmo da obtenção da expressão linguística pela criança (Bruner, 2008). A comparação conceitual a Gramsci se deve à contribuição deste na proposta de um pensamento crítico para a ruptura do senso comum e de ideologias hegemônicas opressoras, dentre outros modos, através da educação. Diante das pistas oferecidas, questionamos: se a estrutura narrativa possibilita compreensões ainda pré-linguísticas de significados, haveria já o início de uma internalização do racismo, constituindo preconceitos raciais, anterior mesmo à expressão linguística pela criança?

É essa questão que pretendemos trazer aqui ao buscar o lugar da narrativa em Bruner, fazendo uma ponte com os conceitos gramscianos de hegemonia, ideologia e senso comum. Mediante o conceito do primeiro autor de self transacional, sugerimos pensarmos em qual seria o provável momento de gênese da internalização de uma ideologia racista e do processo de apropriação do preconceito racial em crianças. O recorte, tão específico dentre os textos escolhidos dos dois pensadores, é proposital: com estas propostas de análise, abrimos caminho a um aprofundamento progressivo em nossas investigações nas ciências humanas, tendo por objetivo contribuir com reflexões acerca de modos possíveis de se combater a apropriação e o enraizamento do preconceito racial em nós e entre nós.

\section{O Lugar da Narrativa em Bruner}

Em sua obra Actos de Significado, Bruner descreve o próprio ingresso na vida humana localizando-a num cenário narrativo: seria como se entrássemos numa peça em movimento, "cuja trama aberta determina as partes que podemos representar e os desfechos para que nos podemos orientar" (Bruner, 2008, p. 52). Seu intuito, com esse cenário, é inverter a relação tradicional entre biologia e cultura a respeito da natureza humana. Ele propõe uma concepção em que é a cultura, e não a biologia, que dirige ou configura a ação e a experiência dos seres humanos, dando forma à vida e à mente humanas e conferindo significado à ação. Isso ocorre através da imposição de "padrões inerentes aos sistemas culturais simbólicos - a sua linguagem e modos de discurso, as formas de explicação lógica e narrativa, e os padrões reciprocamente dependentes da vida comunitária" (Bruner, op. cit., p. 52).

Será na base da cultura que o autor nomeará uma psicologia cultural e a psicologia comum, que é instrumento constitutivo de todas as culturas. É um conjunto de descrições sobre como os seres humanos funcionam, como são as nossas mentes e as dos outros, sobre modos de vida, dentre outras coisas. Bruner indica a psicologia comum como sistema pelo qual as pessoas organizam suas experiências no mundo social e seus conhecimentos sobre o mesmo. Aqui, a narrativa entra como princípio organizador, ou seja, a narrativa organiza a experiência, edificando-se "à volta das expectações estabelecidas ou canônicas e a gestão mental dos desvios de tais expectações" (Bruner, op.cit, p. 54). Estando na base de qualquer psicologia cultural, a psicologia comum teria como componentes nucleares as crenças ou suposições elementares acerca de situações humanas; e é somente quando as crenças constitutivas numa psicologia comum são violadas que as narrativas se constroem.

A narrativa se ressalta em Bruner como conceito que difere de outras formas de discurso e de outros modos de experiência organizadora. A sequencialidade é sua principal propriedade, sendo que a sequência de eventos e estados mentais em si não têm significado próprio; este é dado pelo seu lugar na sequência como um todo - o enredo ou fábula. Ela pode ser real ou imaginária, mantendo seu poder como história; e, como característica crucial, ela "se especializa em forjar laços entre o excepcional e o vulgar" (Bruner, 2008, p. 67). É daí que Bruner examina um aparente dilema: a psicologia comum, ao mesmo tempo em que se centra no que é esperado e usual na condição humana, investindo-se, pois, de canonicidade, possui meios teleologicamente estruturados para compreender o excepcional e o raro, porque a viabilidade de uma cultura está na sua capacidade de resolver conflitos e de explicar diferenças e de renegociar significados comunitários.

Neste ponto, a narrativa, sob outra análise, ocupa um lugar político na teoria de Bruner, enquanto orientadora de formas de organização humana, estabelecendo-se uma conexão entre cultura e ação. De fato, para Bruner, na base da ação humana e, portanto, de sua intencionalidade, existem aspectos de origem cultural. Assim sendo, a cultura vista como um modo de lidar com os problemas humanos impõe modelos que fazem parte de seus sistemas simbólicos. Entre estes podemos considerar as modalidades linguísticas e de discurso e as formas de explicação 
lógicas e narrativas. Desta maneira, os significados compartilhados ao interior de uma mesma cultura atuam como elementos balizadores das ações humanas individuais e lhe dão sentidos. Cultura é, assim, um sistema simbólico, na esteira de Cliffort Geertz (1973), que traz ferramentas e procedimentos para entender e se relacionar com o mundo, ou seja, "procedimentos interpretativos para clarificar os desvios das normas significativas em termos de padrões estabelecidos de crença" (Bruner, 2008: 68).

Tais padrões estabelecidos de crença se configuram numa dimensão também normativa. Por esperar que as pessoas se comportem conforme a situação, constituem regras sociais, valendo, esta "regra da situação" - que Bruner retira de Roger Barker (1978) - tanto para a fala quanto para ação. Enquanto as pessoas se comportam conforme a situação, sendo isto o habitual, experimenta-se o canônico, sendo este autoexplicativo, já que não temos de perguntar o porquê de alguém se comportar como o esperado. Por outro lado, ao nos depararmos com uma exceção ao habitual, encontraremos relatos que contenham as razões ou especificações de um estado intencional, relato que é "quase invariavelmente uma descrição de um mundo possível, em que a excepção encontrada é, de alguma forma, realizada para gerar" (Bruner, 2008: 69).

É neste ponto que sugerimos fazer uma breve comparação de tais padrões estabelecidos de crença aos processos hegemônico-ideológicos e ao senso comum que Antonio Gramsci (tradução, 2004) analisa no viés da cultura. Esses conceitos se relacionam com os questionamentos levantados por Bruner quando este propõe o conceito de consciência histórica, vista como consciência de ordem superior, peculiar do ser humano. Essa consciência é capaz de organizar a ação de forma original, em contraposição à ativação de uma consciência que se poderia definir como primária, isenta de narrativas do passado e de antecipações do futuro. Estabelece-se assim uma conexão entre consciência e narrativa: enquanto a consciência torna-se um instrumento que possibilita escrever a história das pessoas e de atribuir-lhe significados, a capacidade de narrar e registrar de alguma forma, por sua vez, possibilita mediar entre o mundo canônico da

1. Especifico a interpretação de Bobbio e Hall do conceito gramsciano de hegemonia porque, na multiplicidade das investigações a respeito de Gramsci, hegemonia não é um conceito consensualizado. Autores como Luciano Gruppi, Norberto Bobbio, Nicola Auciello e Stuart Hall, por exemplo, se diferenciam na interpretação, dentre outros aspectos, da relação entre dominação e direção, além de haver discordâncias quanto à restrição ou não da hegemonia ao fundamento estruturaleconômico. Bobbio (1982) e Hall (2003) defendem que a hegemonia está também relacionada aos aspectos culturais e não apenas estruturais-econômicos, e é a essa concepção que filio, ao menos até agora, as minhas reflexões. As variadas interpretações ocorrem pela extensão dos escritos de Gramsci e as reconstruções conceituais ao longo de suas cartas e de seus escritos do cárcere. cultura e o mundo das esperanças, desejos e crenças. Para Bruner, a característica própria da narrativa é a de gerir os desvios em relação ao considerado canônico, que corresponde à norma. Elaborar uma história possibilita dar-lhe um sentido, um significado a um evento ou comportamento. Assim, a narrativa torna-se algo capaz de estruturar a experiência, o que leva Bruner a defini-la como uma sequência de eventos, estados mentais, situações que envolvem os seres humanos como personagens ou como atores.

Apresenta-se-nos, assim, a possibilidade de se questionar como as narrativas, enquanto organização das experiências, são decorrentes das ideologias, e ao mesmo tempo trazem em si instrumentos possíveis de mudanças ideológicas. Mais adiante, interseccionarei esse questionamento ao conceito de self transacional e empréstimo de consciência para trazer a indagação de como o canônico se relaciona com a apropriação do preconceito racial na criança.

\section{Uma ponte ideológica: trazendo Gramsci ao diálogo}

Bruner, como vimos acima, apresenta a experimentação do canônico, ou seja, o comportamento conforme o esperado dentro dos padrões estabelecidos de crenças, surgindo a narrativa no desvio ou ruptura desse canônico.

Nossa proposta visa então a examinarmos o canônico de Bruner numa articulação com o conceito de hegemonia - que só se identifica, do mesmo modo, pela contra-hegemonia subjacente que representa a sua ruptura. Utilizando a perspectiva de Norberto Bobbio (1982) e Stuart Hall (2003) do conceito gramsciano de hegemonia $^{1}$, podemos identificar as relações de poder como manifestas em todos os campos da vida em nossa sociedade, a partir de diversos sujeitos sociais não apenas de um grupo específico e individualizado. Isso porque a "hegemonia gramsciana (...) abarca, como suas entidades portadoras, não só o partido, mas todas as outras instituições da sociedade civil (...) que tenham um nexo qualquer com a elaboração e a difusão da cultura" (Bobbio, 1982, p. 48).

O domínio desta hegemonia vem a partir de um determinado grau de consentimento geral, popular; o que lidera esse consentimento não é uma classe dominante, ou seja, um sujeito uno, indivisível, sem antagonismos, mas um bloco histórico, o que indica dizer que uma liderança hegemônica pode ser apenas uma fração do agente hegemonizador. Em outras palavras, cada formação hegemônica terá a sua própria configuração e composição social complexa: cada um dos agentes significa apenas uma fração do agente hegemonizador mais complexo e mais profundo, que busca permanentemente o consentimento geral e popular.

Tal complexidade dessa composição social não permite que se reduza a luta entre forças sociais e políticas em dois blocos históricos polarizados (de 
classes), simples e homogêneos. A hegemonia é um termo geral e analítico, que pode ser aplicado às alianças de vários grupos sociais e ser conduzida em vários campos da vida humana (Hall, 2003).

O que é relevante para a compreensão das relações que parecem existir entre o conceito gramsciano de hegemonia e o conceito de Bruner do canônico é quanto ao aspecto normativo que ambos assumem, e de que forma essa normatividade se apresenta nas relações sociais. Gramsci usa uma série de distinções entre a dominação - que precisa recorrer continuamente aos meios coercitivos, como polícia, exército, etc. -, e a direção da hegemonia-que também possui um aspecto coercitivo, mas que é conduzida pela conquista do consentimento, pela consideração dos interesses de quem se quer subordinar e pela tentativa de se tornar aceito popularmente; da mesma forma, distinguem-se porque os campos englobados pela hegemonia não são somente o econômico e o administrativo, mas também os domínios da liderança cultural, moral, ética e intelectual, dentre outros (Hall, 2003; Gramsci, tradução, 2004).

Ou seja, as ideologias hegemônicas, se não recorrem constante e explicitamente ao caráter coercitivo direto como seria numa ideologia dominante, buscam conduzir um consentimento popular nos diversos campos da experiência humana. Tal consentimento no domínio da cultura poderá, por essa análise, resultar os tais padrões estabelecidos de crença referidos por Bruner.

Num estudo sobre a história da cultura, em seus Cadernos, Gramsci defende que "todos os homens são "filósofos"'. Tal filosofia espontânea, como nomeia, está contida na linguagem, no senso comum e no bom senso (sendo o bom senso o "núcleo sadio" do senso comum, porquanto tenha uma direção consciente), na religião popular e em "todo sistema de crenças, superstições, opiniões, modos de ver e de agir" (Gramsci, tradução, 2004, p. 93). Após demonstrar que todos os homens são filósofos e que há uma filosofia espontânea, reconhece um segundo momento: o momento da crítica e da consciência. E este momento traz em si o seguinte problema:

(...) é preferível "pensar" sem disto ter consciência crítica, de uma maneira desagregada e ocasional, isto é, "participar" de uma concepção do mundo "imposta" mecanicamente pelo ambiente exterior, ou seja, por um dos muitos grupos sociais nos quais todos estão automaticamente envolvidos desde sua entrada no mundo consciente (...) ou é preferível elaborar a própria concepção do mundo de uma maneira consciente e crítica e, portanto, em ligação com este trabalho do próprio cérebro,

2. O conceito de ideologia assume em grande parte a definição de "concepção de mundo" em Gramsci: “(...) uma 'ideologia' [em seu] significado mais alto de uma concepção do mundo, que se manifesta implicitamente na arte, no direito, na atividade econômica, em todas as manifestações de vida individuais e coletiva (...)" (Gramsci, 2004, pp. 98-99). escolher a própria esfera de atividade, participar ativamente na produção da história do mundo, ser o guia de si mesmo e não aceitar do exterior, passiva e servilmente, a marca da própria personalidade? (Gramsci, op. cit., pp. 93-4).

Fazendo uma leitura de Gramsci à luz de Bruner, a consciência crítica proposta seria a base de uma ruptura da canonicidade social - tal ideologia ou concepção do mundo "imposta" pelo ambiente exterior ${ }^{2}$. Somente através desta ruptura será possível ao sujeito constituir uma narrativa social transformadora - ou seja, como protagonista, participar ativamente na produção da história do mundo.

Tal leitura, aqui proposta, se insere na análise de Bruner do papel da psicologia comum narrativizada num contexto mais alargado, que ele chama de organização da experiência, papel do qual ele ressalta dois temas: o esboço ou esquematização e a regulação do afeto. O esboço é o que "fornece um meio de 'construir' um mundo, de caracterizar o seu fluxo, de segmentar acontecimentos dentro deste mundo e assim por diante" (Bruner, 2008, p. 77). Sem essa capacidade de esquematização, afirma, nos perderíamos como espécie, sendo a forma narrativa a forma típica de se esquematizar a experiência e a nossa memória dela. Essa experiência no mundo social, bem como a memória que temos dele, "estão poderosamente estruturadas não só por concepções profundamente interiorizadas e narrativizadas da psicologia comum, mas também pelas instituições historicamente enraizadas que uma cultura elabora para as apoiar e reforçar" (Bruner, op. cit., p. 79). Dando um exemplo de tais instituições historicamente enraizadas, Bruner cita o exemplo de Scott Fizgerald (s/d) de que os muito ricos são diferentes não só porque têm fortunas, mas também porque são vistos como diferentes e atuam como tal; e até mesmo a "ciência" reforça estas percepções e suas transformações da memória. Cynthia Fuchs Epstein (1988), cita Bruner, demonstrou "como os estereótipos de gênero eram sistematicamente acentuados e exagerados pela escolha selectiva dos instrumentos de pesquisa para os medir" (Bruner, op.cit., p. 79).

Da mesma forma, há imposições culturais de modos de dirigir e regular o afeto, para uma manutenção da coesão cultural; seguindo o pensamento de Bartlett (1932) nesse sentido, Bruner observa que quaisquer tendências conflituosas suscetíveis de ameaçar a vida social podem servir também para desestabilizar a organização da memória. Avançando sobre essa compreensão, compreende que os processos “implicados em 'ter e manter' a experiência são informados pelos esquemas embebidos das concepções psicológicas comuns do nosso mundo as crenças constituintes e as narrativas de escala mais vasta que os inserem nas configurações ou enredos temporais" (Bruner, op.cit., p. 81).

É em termos das esquematizações e estruturação 
mais larga dos eventos do mundo ou dos enunciados do texto para a compreensão dos fenômenos culturais que se situa o significado. Tais estruturas mais amplas vão fornecer um contexto interpretativo para os seus componentes. Somente se formos capazes de especificar a estrutura e a coerência dos amplos contextos em que significados específicos se criam e transmitem, seremos capazes de interpretar os significados e a sua formação. Interpretando a vida em ação, afirma Bruner, a narrativa lida com o material dessa ação, assim como da intencionalidade humana, relacionando-se com o significado dado às coisas pelo sujeito narrador e envolvendo a negociação de significado entre as pessoas (Bruner, 2008; Correia, 2003).

Certamente, o diálogo entre Bruner e Gramsci assumirá diversos outros contextos pelo estudo mais aprofundado da própria ambiência política vivenciada pelos dois pensadores. No movimento inverso, interpretar a negociação de significado à luz de Gramsci conduziria a maiores reflexões acerca do sentido político da negociação. Isso porque se Bruner advoga que a viabilidade de uma cultura está na sua capacidade de resolver conflitos e de explicar diferenças e de renegociar significados comunitários, Gramsci defende, em seu ponto de vista marxista, uma ruptura crítica do que é hegemonicamente direcionado para viabilizar a emancipação do senso comum para o bom senso.

\section{O Self Transacional e a Apropriação do Preconceito Racial}

A mediação da interpretação narrativa é o que possibilita tal método de negociação e renegociação de significados, dentro de uma perspectiva de construção cultural do significado. Bruner afirma este método enquanto uma das realizações máximas do desenvolvimento humano, em seus sentidos ontogenético, cultural e filogenético. No sentido cultural, tem por suporte os recursos narrativos armazenados de uma comunidade e toda uma gama de técnicas interpretativas para localizar e resolver narrativas divergentes; no sentido filogenético, é suportado por uma capacidade cognitiva primordial nos importantes primatas para reconhecer e explorar as crenças e os desejos de seus semelhantes (Bruner, 2008).

Essa capacidade cognitiva se relaciona ainda com o self transacional - um self em negociação com o mundo social circundante, visto que o self é uma construção, um resultado de ação e simbolização (Correia, 2003).

As transações, aqui, ressaltam as negociações estabelecidas na partilha mútua de pressupostos e concepções de mundo, de como a mente funciona e o que os outros vão fazer; assim, o self transacional se relaciona com a capacidade cognitiva de termos algum acesso às mentes dos outros, numa presunção do que os outros fazem ou dizem. Essa presunção regularia uma organização de nossas ações ou a percepção da mente do outro (Correia, 2003).

Sendo, o significado, um fenômeno culturalmente mediado, depende não apenas de um signo e de um referente, mas também de um interpretante, uma representação do mundo, que medeia a relação do signo-referente. Na distinção de Peirce (1960) entre ícone, índice e símbolo, o símbolo surge dependente de um sistema de signos de modo que a relação de um signo e seu referente é arbitrária e governada somente por sua posição dentro desse sistema que define o que ele simboliza; aqui, os símbolos dependem da existência de uma linguagem que contém um sistema de signos, e é do modo crítico da capacidade humana de interiorizar uma linguagem e usar o seu sistema de signos como interpretante de que depende o significado simbólico (In Bruner, 2008).

Nesse ponto, Bruner se refere às questões acerca da aquisição inicial da linguagem na criança, em busca de uma biologia do significado que não apele meramente ao inatismo. Das investigações estudadas, o autor levanta três asserções: 1) que "a aquisição da linguagem na criança requer (...) assistência e interacção com as pessoas que por ela olham" mais do que se suspeitou até então; 2) que "Certas funções ou intenções comunicativas encontram-se já bem implantadas antes de a criança dominar a linguagem formal para linguisticamente as expressar", e, assim, “(...) a criança está parcialmente motivada para dominar a linguagem a fim de melhor realizar estas funções [indicar, rotular, pedir e confundir] in vivo"; e 3) que "a aquisição de uma primeira língua é muito sensível ao contexto" (Bruner, 2008, pp. 91-92), do que se entende que há um melhor progresso quando a criança já compreende o significado do que se fala ou da situação em que a conversa ocorre. Para o autor, o modo como entramos na linguagem se baseia num conjunto de disposições pré-linguísticas para o significado, ou seja, representações protolinguísticas do mundo anterior à linguagem, cuja plena realização, porém, depende do "utensílio cultural da linguagem". Esta disposição pré-linguística é "uma representação altamente maleável, embora inata, que é desencandeada através dos actos e expressões dos outros e por meio de alguns contextos sociais básicos em que os seres humanos interagem" (Bruner, op. cit., p. 93). Em outras palavras, já vimos equipados com um conjunto de pré-disposições para construir o mundo social de certa maneira, com uma forma primitiva de psicologia comum, como uma característica da práxis. São os tipos de representações etnopsicológicas que ele propõe, ressaltando o aspecto sociocultural de suas análises.

$\mathrm{O}$ esforço de Bruner se deve ao seu empenho intelectual em demonstrar o papel da interação social na aquisição da linguagem, situando-a anterior mesmo à sua expressão ampla ou compreensão pela criança. 
Defende que, mesmo antes de emergir a linguagem, "não se pode interagir humanamente com os outros sem alguma 'teoria da mente' protolinguística" (Bruner, op. cit., p. 96). Seguindo tal compreensão, podemos entender a teoria da mente por uma "(...) habilidade de compreender seus estados mentais e os de outras pessoas com as quais interagem (...) e de utilizarem esta informação para explicar e predizer o comportamento" (Roazzi e Santana, 1999, p. 307), habilidade presente, para Bruner, já anteriormente à aquisição linguística.

Tal capacidade cognitiva, própria aos seres humanos, apresenta-se, por exemplo, na intervenção de um mais velho ou mais capaz, que faria uma espécie de empréstimo de consciência ao mais novo numa transação negociável, tendo por suporte o contexto, o situado, com o auxílio de meios de base biológica que nos possibilitaria tal "leitura" da mente dos outros. No entanto, a base biológica atua aqui enquanto restrição, sendo a cultura e a busca do significado a "mão modeladora" dos tais meios (Correia, 2003).

Com base nestas compreensões, em suma, Bruner defende a existência de uma teoria da mente protolinguística, inerente ao comportamento humano e da qual emergem realizações linguísticas. Afirma que o jovem ser humano obtém ou realiza o poder da narrativa por esta disposição protolinguística da organização narrativa, através do interesse na interação humana em seu contexto cultural e histórico, da capacidade de manter uma ordem sequencial dos eventos e estados, e de uma disposição prematura de percepção do que é canônico e do que viola essa canonicidade, seguindo uma "perspectiva do narrador". Portanto, essa predisposição inata é equipada e desenvolvida pela cultura, da qual se obtém novos poderes de narração (Bruner, 2008).

Perseguindo a pergunta-geradora deste estudo, de se haveria uma internalização do racismo, constituindo preconceitos raciais anterior mesmo à ampla expressão linguística da criança, pela disposição protolinguística da organização narrativa, compreendemos que sim.

O racismo se constitui, numa interpretação gramsciana, em ideologia que busca direcionar um consenso de suposta superioridade de uma raça sobre outras (Hall, 2003). Adota no Brasil características bastante peculiares que começam por um processo colonizador e escravista nas Américas, tendo este processo encontrado "no racismo uma justificativa ideológica" (Gorender, 2000, p. 55), porque fora baseado na inferiorização dos segmentos negros e indígenas.

Como categoria estrutural de nossa sociedade, o racismo impõe ao sujeito negro um modelo de identificação normativo, que é o modelo branco, a idealização da brancura. A construção social acerca do conceito de raça no Brasil indica historicamente um locus da opressão racista: a imagem e o corpo da pessoa negra, compreendendo-a num conjunto indissociável às suas manifestações intelectuais, culturais e espirituais. O custo emocional do racismo, usando uma expressão de Neuza Santos Souza (1983), está na destruição do sentimento positivo de uma pessoa negra por si mesma, ainda mais quando sua identidade histórico-existencial é completamente invisibilizada através da negação do ser negro em sua perspectiva política e cultural. A relação entre o sentimento por si, a autoestima, e o fortalecimento político e econômico é indissociável porque, tendo de se livrar "da concepção tradicionalista que o definia econômica, política e socialmente como inferior e submisso, e não possuindo uma outra concepção positiva de si mesmo, o negro viu-se obrigado a tomar o branco como identidade"(Souza, 1983, p. 19). Essa identidade tomada, no entanto, é constantemente desmentida ao ser a pessoa negra sempre identificada como o outro no interior das relações interpessoais e das relações sociais.

O resultado é a rejeição "levada ao nível do desespero" (Souza, op.cit., p. 35), iniciada desde a infância, que violenta o corpo físico:

(...)me achava muito feia, me identificava como uma menina negra, diferente: não tinha nenhuma menina como eu. Todas as meninas tinham o cabelo liso, o nariz fino. (...) Depois eu fui sentindo que aquele negócio de olhar no espelho era uma coisa ruim. Um dia eu me percebi com medo de mim no espelho! Tive uma crise de pavor. (Luísa, In Souza. op.cit., p. 35)

Acobertado por práticas culturais, o racismo busca associar os aspectos fenotípicos a elementos desumanizadores ou depreciadores da pessoa negra. Deste modo, como ideologia hegemônica, busca conduzir um consenso acerca de lugares raciais que organiza a experiência e a memória da sociedade brasileira através de formas narrativas cujo canônico é tal modelo de identificação normativo, ou seja, o modelo branco, e o elemento negro é o desvirtuante, a quebra deste canônico. De fato o racismo, além de ser algo congênito com a modernidade, se nutre e ganha força através do uso de narrativas e termos de cunho racistas, os quais contribuem na formação de um imaginário comum que enxerga nos outros uma ameaça concreta e real geradora de medo e incertezas. Tais formas narrativas surgem, portanto, como estruturação de uma "memória" histórica justificadora das desigualdades raciais, como legitimação dos lugares "próprios" de cada grupo racial na sociedade. Sendo o modelo branco canonicamente o belo e o bom, o elemento negro, destoando deste modelo, será o desvirtuamento do belo e do bom - portanto, o feio e o ruim.

Um modelo canônico branco se transparece em formas narrativas na literatura, por exemplo, em relação ao lugar dos personagens na narrativa literária. Em uma pesquisa a respeito das relações raciais na literatura brasileira contemporânea, Regina 
Dalcastagnè (2008) apresentou um mapeamento dos romances brasileiros, publicados nos 15 anos anteriores pelas principais editoras do país, que identificou quase $80 \%$ de personagens brancas. Os brancos são quase quatro quintos das personagens, sendo que em $56,6 \%$ dos romances não há nenhuma personagem não-branca.

A predominância branca se reforça principalmente entre os protagonistas, especialmente os narradores. Enquanto que, no tocante à cor e posição das personagens, $84,5 \%$ dos protagonistas eram brancos, $5,8 \%$ eram negros e também $5,8 \%$, por definição da autora, "mestiços". Sendo 7,9\% das personagens, os negros são apenas $2,7 \%$ dos narradores, os "mestiços" $3,8 \%$, ao passo que os brancos são $79,8 \%$. Em termos de gênero, as mulheres negras mal aparecem: são 223 protagonistas homens - 206 brancos e 17 negros para 86 protagonistas mulheres - dentre elas, somente 3 negras. Quanto aos narradores, os homens são 201 - 107 brancos e 4 negros -, e as mulheres $53-52$ brancas e 1 narradora negra apenas (Dalcastagné, 2008).

Mas não apenas a representatividade numérica indica a existência de um modelo canônico branco. Também as características das personagens racialmente identificadas reforçam a ideia de que o negro é o elemento desvirtuante. A pesquisa identificou que $33 \%$ das crianças e $56 \%$ dos adolescentes negros personagens do romance atual brasileiro usam drogas e são dependentes químicos, quando somente $4 \%$ das personagens crianças e $8 \%$ dos adolescentes brancos assim são retratados. Quanto às ocupações das personagens fica bastante nítida a existência de um modelo racista: as principais ocupações das personagens brancas são dona de casa $(9,8 \%)$, artista $(8,5 \%)$, escritor $(6,9 \%)$, estudante $(6,3 \%)$, sem ocupação $(6,1 \%)$; já das personagens negras, as principais ocupações são bandido/contraventor (20,4\%), empregado(a) doméstico(a) (12,2\%), escravo $(9,2 \%)$, profissional do sexo $(8,2 \%)$ e dona de casa $(6,1 \%)$. Para a autora, ainda é necessário lembrar à sociedade que os negros são humanos, "quando se percebe que sua animalização se mantém como um 'recurso' literário", como nos exemplos dados de "O negro", de Dalton Trevisan (1968) e "O negro e as cercanias do negro", de Haroldo Maranhão (2001), em que o homem negro surge como animal sujo diante da mulher branca (Dalcastagnè, 2008: 98).

Nesse mesmo sentido, em 2012 fizemos um levantamento das fotos de capas de duas revistas nacionais a respeito de crianças, a revista Pais\&Filhos e a revista Crescer, no período de março de 2011 a março de 2012. Em 26 volumes, 13 edições de cada revista, $100 \%$ das capas foram ilustradas exclusivamente com crianças brancas - não houve, em 13 meses, nas duas revistas referenciais no assunto de cuidado infantil, nenhuma criança negra como modelo (Duarte, 2012, In http://encrespoenaoaliso.blogspot.com.br/).
A replicação social dessa estruturação do modelo canônico branco está exaustivamente demonstrada nas pesquisas de psicologia e educação realizada entre crianças. Buscando aprofundar a reflexão sobre o modo pelo qual a criança se vê e se avalia na escola, Ivone Martins de Oliveira (2009) desenvolveu pesquisa em 1990 numa sala da então $3^{\text {a }}$. série de uma escola municipal em Campinas, com crianças entre 10 e 13 anos, para procurar responder à indagação de como as crianças discriminadas racialmente viviam as situações discriminatórias, e se essas situações interferiam na elaboração da imagem que a criança faz de si mesma na escola. Observou, inicialmente, que as descrições de si mesmos e os aspectos mais ressaltados nessas autodescrições diziam respeito aos atributos físicos referentes à cor de pele, cor e tamanho dos cabelos, cor dos olhos, idade, estatura e peso. Ressalvou as enunciações acerca de duas alunas consideradas "pretas" pelos colegas, recebendo, por estes, chamamentos como "noite", "escuridão" e "feia" (Oliveira, 2009).

Uma das pesquisas realizadas por França e Monteiro, em Sergipe (2002), analisou o efeito da cor da pele e da idade sobre a identidade e a preferência raciais. As autoras demonstraram que havia uma forte tendência ao "branqueamento" entre as crianças sergipanas, influenciadas pela idade ou seja, a preferência do "mulato" pelo branco e do negro pelo "moreno". Enquanto as crianças negras de 5 a 8 anos afirmaram não gostarem de ser negras, as "mulatas" percebiam sua identidade racial num meio termo entre positiva e negativa, e as crianças brancas, independentemente da idade, possuíam uma identidade racial positiva. Em outra pesquisa das mesmas autoras (2004), não apenas a identidade racial positiva é perceptivo entre as crianças brancas, mas também manifestações de preconceito racial. $\mathrm{O}$ estudo realizado com três grupos de crianças brancas de 05 a 10 anos, sendo que em um grupo também as mães foram entrevistadas, demonstrou que, enquanto as crianças expressam preconceito contra o grupo de negros, suas mães acham que é antinormativo ter preconceito contra eles. Para as pesquisadoras, isto significa que "as crianças desta idade ainda não interiorizaram a norma expressa pelos adultos de referência, norma esta que impede a expressão directa do preconceito contra este grupo" (França e Monteiro, 2004. p. 717). No grupo de crianças de 8 a 10 anos, no entanto, as crianças não se diferenciaram de suas mães quanto às suas atitudes em relação ao grupo de negros, demonstrando que "as crianças desta idade interiorizaram o padrão normativo de seu grupo de referência para emitir avaliações directas sobre o grupo dos negros" (França e Monteiro, op.cit.: 717).

A esse respeito, Iolanda Oliveira (1999) também trouxe como objeto de preocupação os aspectos afetivos em crianças negras de baixa renda entrevistadas que "representam a recusa de 
ser afro-descendente... parecendo que os sujeitos acreditam na própria inferioridade como componente natural e irreversível" (Oliveira, 1999, p. 105); isto porque, segundo a autora, a ascendência africana e a pobreza no Brasil criaram significados sociais que estigmatizaria o fenótipo negro enquanto indicador de pobreza, estigmas confirmados na pesquisa realizada com desenhos de moradias entre crianças negras e brancas.

Estas pesquisas demonstram como o racismo já influencia fortemente as relações entre crianças, e como isso constrói um autoconceito positivo em crianças brancas e um autoconceito negativo em crianças negras. Pouco sabemos, no entanto, quando o racismo é apropriado entre as crianças para a construção de suas relações interpessoais e de seus autoconceitos. Porém, recuperando nossa análise de Bruner, pela disposição pré-linguística de se perceber o que é canônico e o que é inabitual, deduzimos que antes mesmo de expressar amplamente a linguagem, portanto, a criança percebe, no contexto da interação social, que o canônico é o modelo branco, sendo o negro o desvirtuamento ou a ruptura do mesmo. Assim, está prematuramente sujeita à internalização de preconceitos raciais, resultando na reprodução de atitudes racistas, por parte das crianças brancas, e em uma baixa autoestima ou negação de seu pertencimento racial, por parte de crianças negras. Abre-se campo à apropriação da ideologia racista no desenvolvimento de sua expressão linguística pelas práticas culturais, situadas num contexto sociopolítico de desigualdades raciais históricas que legitimam tais práticas.

Por uma reorganização da memória coletiva: considerações acerca de uma narrativa crítica transformadora

Por outro lado, à medida que a internalização de preconceitos raciais se desenvolve num contexto sociopolítico racista, multiplicando práticas culturais discriminatórias, a canonicidade se estabelece na relação mesma de desigualdade branco/negro; ou seja, a experiência humana é organizada padronizando aquele desequilíbrio como habitual, comum, consensual, mantendo o modelo branco como normativo e o negro como desvirtuante. Sendo a própria relação de desigualdade branco-negro o canônico, as discriminações e segregações resultantes são naturalizadas de um modo que não parece incomodar substancialmente a sociedade tais assimetrias que se afiguram nos índices socioeconômicos. O senso comum não somente banaliza essa situação como a corrobora e a reproduz, mantendo o que Helio Santos (2003) denomina de "círculo vicioso" do racismo brasileiro. Quando, portanto, uma criança branca reproduz nos atos de fala e no seu discurso um sentimento de superioridade, ou uma criança negra demonstra baixa autoestima por um sentimento de inferiorização, estão apenas exteriorizando o que já havia sido internalizado preconceitualmente pela estruturação narrativa pré-linguística da experiência do racismo na práxis da interação social.

É daí que vemos em Gramsci, e em sua proposta de ruptura crítica do senso comum, a possibilidade da resistência ao processo direcionado de convencimento por uma ideologia hegemonizadora; em nosso caso, a resistência à hegemonia racista que naturaliza, torna habitual - canônico, pois - os estereótipos racistas, as desigualdades e as discriminações. Pode vir a surgir, nesse viés, uma narrativa social transformadora que, rompendo criticamente com uma concepção de mundo imposta por grupos hegemônicos, possibilite novas concepções de mundo, contra-hegemônicas e em hegemonização crítica, nas quais o bom senso traduzir-se-á na equidade entre negros e brancos.

Para a substituição de um senso comum e de velhas concepções de mundo, a contribuição gramsciana defende um modo didático de argumentação persistente dentro de um movimento cultural crítico sobre a mentalidade popular, bem como defende trabalhar educativamente na formação de uma intelectualidade orgânica, combatendo-se o "elemento amorfo da massa". Assim, para Gramsci, será possível modificar-se o "panorama ideológico" de uma época (Gramsci, tradução, 2004, p. 110). É a educação, portanto, que surgirá aqui como via de construção de uma narrativa social transformadora, numa nova organização das ações e experiências humanas e da própria memória destas.

Com isto, acreditamos termos um bom tema para poder pensar em pesquisas com crianças sobre a apropriação do racismo e para discutirmos proposições de formas educativas - pensando em educação de modo amplo e em um contexto políticocultural - de combate à internalização e apropriação do racismo na infância. Mas esta já é outra história. Fica, por enquanto, a proposta de aprofundamento do assunto para estudos e reflexões posteriores.

\section{Referências}

Barker, R. G. (1978). Habis, Environments, and Human Behaviour. São Francisco: Jossey-Bass.

Bartlett, F. C. (1932). Remembering: A Study in Experimental and Social Psychology and Primitive Culture. Cambridge: Cambridge University Press.

Bobbio, N. (1982). O Conceito de Sociedade Civil. Rio de Janeiro: Edições Graal.

Bruner, J. (2002). Realidade Mental, Mundos Possíveis. Porto Alegre: Artes Médicas.

Bruner, J. (2008). Actos de Significado. Tradução de Vanda Prazeres. Lisboa: Edições 70.

Correia, M. F. B. (2003). A constituição social da mente: (re)descobrindo Jerome Bruner e a construção de significados. Estudos de Psicologia, 8(3), 505-513.

Costa, J. F. (1990). Da cor ao corpo: a violência do racismo. In Souza, N. S., Tornar-se Negro: as vicissitudes do negro brasileiro em ascensão social (pp. 01-18). Rio de Janeiro: Graal.

Dalcastagnè, Regina. (2008). Entre silêncios e estereótipos: relações raciais na literatura brasileira contemporânea. Estudos 
de literatura brasileira contemporânea, v. 31, p. 87-110, 2008. Disponível em: http://repositorio.unb.br/handle/10482/9620. Acesso em 14 set. 2013.

Duarte, R. O. (2004), Direito e Negritude: a contribuição do Direito da Construção/Descontrução da Identidade Negra. Monografia do Curso de Especialização em Direitos Humanos da Universidade Federal da Paraíba.

(2006). "Nos Alicerces do Mundo": o Dilema e a Dialética na Afirmação da Identidade Negra. Dissertação de Mestrado em Ciência Política da Universidade Federal de Pernambuco.

(2012). Só os brancos nascem?. Disponível em http://encrespoenaoaliso.blogspot.com.br/2012/03/ so-os-brancos-nascem.html. Acesso em 14 set. 2013.

(2012). Direito de nascer e de crescer.

Disponível em http://encrespoenaoaliso.blogspot.com.br/2012/03/ direito-de-nascer-e-de-crescer.html. Acesso em 14 set. 2013.

Epstein, C. F. (1988). Deceptive Distinctions: Sex, Gender, and the Social Order. New Haven: Yale University Press.

França, D. X. \& Monteiro, M. B. (2002). Identidade racial e preferência em crianças brasileiras de 5 a 10 anos. Psicologia, 16(2), 293-323.

(2004). A expressão das formas indirectas de racismo na infância. In Análise Psicológica, 4 (XXII): 705-720.

Geertz. C. (1973). The Interpretation of Cultures. Nova Iorque: Basic Books.

Gorender, Jacob. (2000). Brasil em Preto \& Branco. São Paulo: SENAC.

Gramsci, A. (2004). Cadernos do Cárcere - Vol. 1 - Introdução

Sobre os autores:

Rebeca Oliveira Duarte - Doutoranda do Programa de Pós-Graduação em Psicologia Cognitiva, Universidade Federal de Pernambuco.

Antonio Roazzi - Professor Titular da UFPE - Coordenador do Núcleo de Pesquisa em Epistemologia Experimental e Cultural (NEC).

E-mail: roazzi@gmail.com 